\title{
Poly( $N$-isopropylacrylamide)-based ionic hydrogels: synthesis, swelling properties, interfacial adsorption and release of dyes
}

\author{
Xianjing Zhou ${ }^{1}$, Jing Wang ${ }^{2}$, Jingjing $\mathrm{Nie}^{2}$ and Binyang $\mathrm{Du}^{1}$ \\ Poly( $N$-isopropylacrylamide)-based ionic hydrogels were synthesized by free-radical polymerization with $N$-isopropylacrylamide as \\ a monomer and imidazolium-based dicationic ionic liquid as a crosslinker. The dicationic crosslinkers $\left[\mathrm{C}_{n}(\mathrm{Vim})_{2}\right][\mathrm{Br}]_{2}$ were \\ obtained by quaternizing 1-vinylimidazole $(\mathrm{Vim})$ with dibromo compounds $\left(\mathrm{Br}-\mathrm{C}_{n} \mathrm{H}_{2 n}-\mathrm{Br}\right)$ with various alkyl chain length $n$, \\ respectively. The effects of alkyl chain length and the amounts of crosslinker on the structure, swelling properties, interfacial \\ adsorption and release of anionic dyes of the obtained ionic hydrogels were systematically investigated by using scanning \\ electron microscopy, Fourier transform infrared spectroscopy and ultraviolet-visible spectroscopy. The obtained ionic hydrogels \\ showed good swelling properties and typical feature of poly(ionic liquid) in aqueous solutions, of which the quaternized \\ imidazolium moieties could interfacially interact with anionic dyes, such as methyl orange, methyl blue, congo red, orange G, \\ thymol blue and bromothymol blue. Different kinetic and adsorption isotherm models were used to describe the interfacial \\ adsorption and release behaviors of anionic dyes, which were strongly dependent on the chemical structures of the dyes. \\ Polymer Journal (2016) 48, 431-438; doi:10.1038/pj.2015.123; published online 20 January 2016
}

\section{INTRODUCTION}

Hydrogels as 'soft-and-wet' materials ${ }^{1}$ are chemically or physically crosslinked three-dimensional networks. They are water insoluble but can absorb a large amount of water (50-90\%) and maintain their semisolid morphology, ${ }^{2-4}$ which have been widely used as drugdelivery systems, tissue engineering, super absorbents, cosmetics, food, sensors and contact lenses. ${ }^{5-16}$ In recent decades, ionic liquids (ILs) have attracted considerable attention in a wide variety of fields because of their excellent properties, such as immeasurably low volatility, high ionic conductivity, non-flammability and high polarity. ${ }^{17-21}$ ILs have also been used as monomers to synthesize polymeric ILs (PILs), which are described as a novel class of materials combining the properties of ILs and the specificities of polymers. ${ }^{22-24}$ The most notable feature of ILs and PILs is that their counter ions can be altered via ion exchange reaction. If IL or PIL moieties were incorporated into the hydrogel crosslinking network, the resultant hydrogel might possess both characteristics of IL or PILs and hydrogel. Such synergetic properties might expand the scope of hydrogel applications and provide enhanced performance in their potential applications. For example, Yan and co-workers, ${ }^{25-27}$ reported the preparation of poly(ionic liquid) gels via host-guest interaction and the applications of ILs for the synthesis of polymeric materials.

Many industries such as textile industries, the leather tanning industry, paper production, food technology, agricultural research, light-harvesting arrays, photoelectrochemical cells and hair colorings have given rise to dye-bearing effluents in their production processes. ${ }^{28,29}$ For aqueous ecosystem, dyes will prevent the sunlight from penetrating into the water and hence impede the photosynthesis. $^{30}$ Some dyes are also carcinogenic, mutagenic and harmful to the human respiratory system. ${ }^{31,32}$ However, discharged dyes in the environment is very difficult to treat, as the dyes have stable and complex chemical structures, as well as low biodegradability. ${ }^{33} \mathrm{~A}$ wide range of methods have been developed for the removal of dyes from waters to decrease their impact on the environment, including adsorption on inorganic or organic matrices, oxidation, decolorization by photocatalysis, microbiological or enzymatic decomposition and so on. ${ }^{34}$

Recently, we have successfully introduced IL moieties into the network of microgels, via the simultaneous quaternized crosslinking reaction during the surfactant-free emulsion copolymerization, leading to a new type of ionic microgels with synergetic properties of IL and microgel. ${ }^{35-38}$ In the present work, we reported the synthesis of poly ( $N$-isopropylacrylamide)-based ionic hydrogels by using $N$-isopropylacrylamide (NIPAm) as the monomer and imidazolium-based dicationic IL as the crosslinker, as shown in Scheme 1. The obtained hydrogels containing quaternized imidazolium moieties exhibited strong interfacial interaction with anionic dyes, which could be potentially used for the removal of anionic dyes from aqueous

\footnotetext{
${ }^{1}$ MOE Key Laboratory of Macromolecular Synthesis and Functionalization, Department of Polymer Science and Engineering, Zhejiang University, Hangzhou, China and ${ }^{2}$ Department of Chemistry, Zhejiang University, Hangzhou, China

Correspondence: Associate Professor J Nie or Professor B Du, MOE Key Laboratory of Macromolecular Synthesis and Functionalization, Department of Polymer Science and Engineering, Zhejiang University, Zheda Road 38, Hangzhou 310027, China.

E-mail: niejj@zju.edu.cn or duby@zju.edu.cn

Received 19 November 2015; revised 28 November 2015; accepted 29 November 2015; published online 20 January 2016
} 


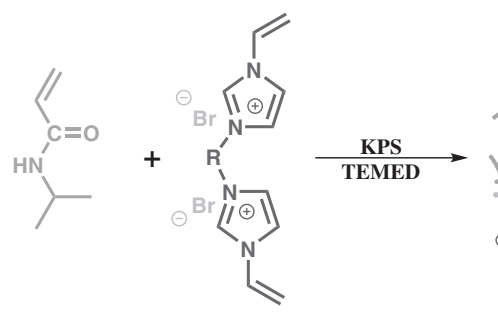

$\left[\mathbf{R}(\operatorname{Vim})_{2}\right][\mathrm{Br}]_{2}$ NIPAm

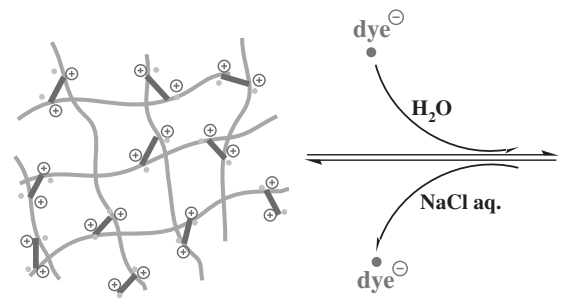

Hydrogel

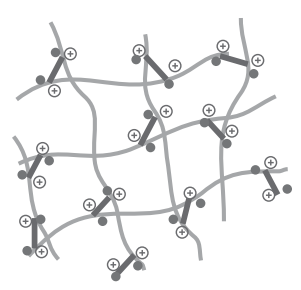

Hydrogel
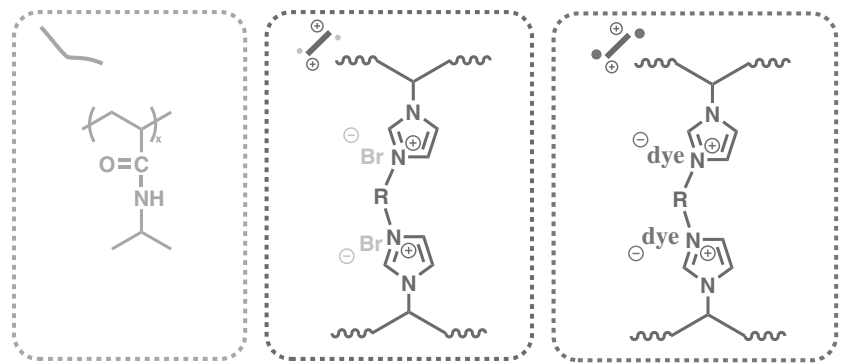

Scheme 1 Synthesis of poly( $N$-isopropylacrylamide)-based ionic hydrogel and its properties of interfacial adsorption and release of anionic dyes. A full color version of this scheme is available at Polymer Journal online.

ecosystem. The effects of alkyl chain length and amounts of crosslinker on the structure, swelling properties, interfacial adsorption and release of anionic dyes of the obtained ionic hydrogels were systematically investigated and discussed.

\section{EXPERIMENTAL PROCEDURE}

\section{Materials}

1-Vinylimidazole (Vim), NIPAm, 1,3-dibromopropane, 1,4-dibromobutane, 1,6-dibromohexane, potassium peroxodisulfate, $N, N, N^{\prime}, N^{\prime}$-tetramethylethylenediamine, $\mathrm{MO}, \mathrm{MB}, \mathrm{CR}, \mathrm{OG}, \mathrm{TB}, \mathrm{BTB}, \mathrm{NaCl}$, methanol and diethyl ether were used as received without further purification.

\section{Synthesis of imidazolium-based dicationic ILs $\left[\mathrm{C}_{n}(\mathrm{Vim})_{2}\right][\mathrm{Br}]_{2}$ $(n=3,4,6)$}

Vim $(15 \mathrm{mmol})$ and dibromo compounds $\left(\mathrm{Br}-\mathrm{C}_{n} \mathrm{H}_{2 n}-\mathrm{Br}\right)(7.5 \mathrm{mmol})$ were dissolved in methanol $(10 \mathrm{ml})$ in a round-bottom flask fitted with a condenser. The dibromo compounds used here were 1,3-dibromopropane $\left(\mathrm{Br}-\mathrm{C}_{3} \mathrm{H}_{6}-\mathrm{Br}\right)$, 1,4-dibromobutane $\left(\mathrm{Br}-\mathrm{C}_{4} \mathrm{H}_{8}-\mathrm{Br}\right)$ and 1,6-dibromohexane $\left(\mathrm{Br}-\mathrm{C}_{6} \mathrm{H}_{12}-\mathrm{Br}\right)$, respectively. Subsequently, the mixture was stirred at $70{ }^{\circ} \mathrm{C}$ for $40 \mathrm{~h}$. The reaction mixture was precipitated from diethyl ether $(100 \mathrm{ml})$, and recrystallized twice in diethyl ether. The products were dried under a vacuum for $24 \mathrm{~h}$ at room temperature. $\left[\mathrm{C}_{n}(\mathrm{Vim})_{2}\right][\mathrm{Br}]_{2}(n=3,4,6)$ were obtained as white solid (yield: $86-92 \%$ ). The ${ }^{1} \mathrm{H}$ nuclear magnetic resonance ( ${ }^{1} \mathrm{H}$ NMR) spectra of $\left[\mathrm{C}_{n}(\mathrm{Vim})_{2}\right][\mathrm{Br}]_{2}$ crosslinkers were shown in Supplementary Figure S1. Vim: ${ }^{1} \mathrm{H} \quad \mathrm{NMR} \quad\left(400 \mathrm{MHz}, \quad \mathbf{D}_{2} \mathrm{O}, \quad \delta_{\mathrm{H}}, \quad\right.$ p.p.m.): $7.76 \quad(1 \mathrm{H}, \quad \mathrm{NCHN}), \quad 7.33$ (1H, $\left.\mathrm{CH}_{2} \mathrm{CHNCHCHN}\right), 6.97$ (2H, $\left.\mathrm{CH}_{2} \mathrm{CHNCHCHN}\right), 5.37$ (1H, $\left.\mathrm{CH}_{2} \mathrm{CHN}\right)$ and $4.92\left(1 \mathrm{H}, \mathrm{CH}_{2} \mathrm{CHN}\right) .\left[\mathrm{C}_{3}(\mathrm{Vim})_{2}\right] \mathrm{Br}_{2}:{ }^{1} \mathrm{H}$ NMR $\left(400 \mathrm{MHz}, \mathrm{D}_{2} \mathrm{O}, \delta_{\mathrm{H}}\right.$,

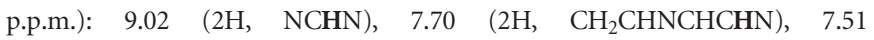
(2H, $\left.\mathrm{CH}_{2} \mathrm{CHNCHCHN}\right), 7.02\left(2 \mathrm{H}, \mathrm{CH}_{2} \mathrm{CHN}\right), 5.72\left(2 \mathrm{H}, \mathrm{CH}_{2} \mathrm{CHN}\right), 5.35$ $\left(2 \mathrm{H}, \mathrm{CH}_{2} \mathrm{CHN}\right), 4.28\left(4 \mathrm{H}, \mathrm{NCH}_{2} \mathrm{CH}_{2} \mathrm{CH}_{2} \mathrm{~N}\right)$ and $2.47\left(2 \mathrm{H}, \mathrm{NCH}_{2} \mathrm{CH}_{2} \mathrm{CH}_{2} \mathrm{~N}\right)$. $\left[\mathrm{C}_{4}(\mathrm{Vim})_{2}\right] \mathrm{Br}_{2}:{ }^{1} \mathrm{H}$ NMR (400 MHz, $\mathrm{D}_{2} \mathrm{O}, \delta_{\mathrm{H}}$, p.p.m.): $8.97(2 \mathrm{H}, \mathrm{NCHN}), 7.68$ (2H, $\left.\mathrm{CH}_{2} \mathrm{CHNCHCHN}\right), 7.47$ (2H, $\left.\mathrm{CH}_{2} \mathrm{CHNCHCHN}\right), 7.02\left(2 \mathrm{H}, \mathrm{CH}_{2} \mathrm{CHN}\right)$, $5.71\left(2 \mathrm{H}, \mathrm{CH}_{2} \mathrm{CHN}\right), 5.33\left(2 \mathrm{H}, \mathrm{CH}_{2} \mathrm{CHN}\right), 4.20\left(4 \mathrm{H}, \mathrm{NCH}_{2} \mathrm{CH}_{2}\right)$ and 1.85 $\left(4 \mathrm{H}, \mathrm{NCH}_{2} \mathrm{CH}_{2}\right) .\left[\mathrm{C}_{6}\left(\mathrm{Vim}_{2}\right] \mathrm{Br}_{2}:{ }^{1} \mathrm{H} \mathrm{NMR}\left(400 \mathrm{MHz}, \mathrm{D}_{2} \mathrm{O}, \delta_{\mathrm{H}}\right.\right.$, p.p.m.) 8.92 $(2 \mathrm{H}, \mathrm{NCHN}), 7.65\left(2 \mathrm{H}, \mathrm{CH}_{2} \mathrm{CHNCHCHN}\right), 7.45\left(2 \mathrm{H}, \mathrm{CH}_{2} \mathrm{CHNCHCHN}\right)$, $7.00\left(2 \mathrm{H}, \mathrm{CH}_{2} \mathrm{CHN}\right), 5.70\left(2 \mathrm{H}, \mathrm{CH}_{2} \mathrm{CHN}\right), 5.32\left(2 \mathrm{H}, \mathrm{CH}_{2} \mathrm{CHN}\right), 4.11$ $\left(4 \mathrm{H}, \quad \mathrm{NCH}_{2} \mathrm{CH}_{2} \mathrm{CH}_{2}\right), \quad 1.78\left(4 \mathrm{H}, \quad \mathrm{NCH}_{2} \mathrm{CH}_{2} \mathrm{CH}_{2}\right)$ and $1.25 \quad(4 \mathrm{H}$, $\mathrm{NCH}_{2} \mathrm{CH}_{2} \mathrm{CH}_{2}$ ). Note that bold of $\mathrm{H}$ represents the description of the characteristics chemical shifts of the proton.
Table 1 Experimental conditions of poly( $\mathrm{N}$-isopropylacrylamide)based ionic hydrogels

\begin{tabular}{|c|c|c|c|c|c|c|}
\hline \multirow[b]{2}{*}{$\begin{array}{l}\text { Sample } \\
\text { codes }\end{array}$} & \multicolumn{2}{|c|}{$\begin{array}{c}{\left[\mathrm{C}_{\mathrm{n}}(\mathrm{Vim})_{2}\right] \mathrm{Br}_{2}} \\
\text { crosslinkers }\end{array}$} & \multirow[b]{2}{*}{$\begin{array}{l}\text { NIPAm } \\
\left(\mathrm{g} m \mathrm{I}^{-1}\right)\end{array}$} & \multirow[b]{2}{*}{$\begin{array}{c}K P S \\
\left(m g m l^{-1}\right)\end{array}$} & \multirow[b]{2}{*}{$\begin{array}{l}\text { TEMED } \\
\left(\mu / \mathrm{m}^{-1}\right)\end{array}$} & \multirow[b]{2}{*}{ Swelling ratio } \\
\hline & $\mathrm{n}$ & $\begin{array}{c}\text { Molar } \\
\text { percenta }\end{array}$ & & & & \\
\hline C3-1.8 & 3 & 1.8 & & & & $61 \pm 6$ \\
\hline C4-1.8 & 4 & 1.8 & & & & $45 \pm 1$ \\
\hline C6-1.8 & 6 & 1.8 & 0.1 & 4 & 4 & $36 \pm 2$ \\
\hline C4-3.6 & 4 & 3.6 & & & & $33 \pm 1$ \\
\hline C4-9.0 & 4 & 9.0 & & & & $20 \pm 3$ \\
\hline
\end{tabular}

Abbreviations: KPS, potassium peroxodisulfate; NIPAm, $N$-isopropylacrylamide; TEMED, $N, N, N$, $N$ '-tetramethylethylenediamine; Vim, 1-vinylimidazole.

a Molar percent of crosslinkers $(\%)=\left[\right.$ crosslinker] $\left(\mathrm{mmol} \mathrm{ml}^{-1}\right) /[\mathrm{NIPAm}]\left(\mathrm{mmol} \mathrm{ml}^{-1}\right) \times 100 \%$.

Synthesis of poly( $N$-isopropylacrylamide)-based ionic hydrogels

The poly( $N$-isopropylacrylamide)-based (PNIPAm-based) ionic hydrogels were prepared by free-radical crosslinking copolymerization of NIPAm and $\left[\mathrm{C}_{n}(\mathrm{Vim})_{2}\right] \mathrm{Br}_{2}(n=3,4,6)$ in aqueous solution with the presence of potassium peroxodisulfate initiator and $N, N, N^{\prime}, N^{\prime}$-tetramethylethylenediamine accelerator at room temperature. Five hydrogels were prepared in the disposable syringes with $5 \mathrm{~mm}$ inner diameter, respectively. Dusts were removed from the reaction solutions by filtering them through Nylon membrane filters with $220 \mathrm{~nm}$ pore size before adding into syringes. The experimental conditions were listed in Table 1 . After $24 \mathrm{~h}$, the obtained hydrogels were taken out from syringes and put into a water reservoir. The water was frequently changed until the unreacted monomer was extracted and the hydrogels reached swelling equilibrium. The swollen hydrogels were then collected and freeze-dried.

\section{Swelling measurements}

The swelling behavior of PNIPAm-based ionic hydrogel was investigated by immersing freeze-dried gels in deionized water at room temperature and recording the amounts of water absorbed at various time intervals. The swelling 
ratio $(S R)$ was determined using the following equation:

$$
S R=\frac{\left(w_{\mathrm{t}}-w_{\mathrm{d}}\right)}{w_{\mathrm{d}}} \times 100 \%
$$

where $w_{\mathrm{t}}$ and $w_{\mathrm{d}}$ are the weight of hydrogel at time $t$ and initial dried weight, respectively. All measurements were replicated at least three times.

\section{Interfacial adsorption and release of anionic dyes in aqueous solution}

A given amount of freeze-dried gels $(0.02 \mathrm{~g})$ with sample codes of C3-1.8, C4-1.8, C6-1.8, C4-3.6 and C4-9.0 were swollen in 50, 50, 50, 100 and $250 \mathrm{ml}$ of $\mathrm{MO}, \mathrm{MB}$ or $\mathrm{CR}$ with a concentration of $0.1 \mathrm{M}$, respectively, for 30 days to reach adsorption equilibrium. Note that the molar ratio of anionic dyes in aqueous solutions to the quaternary Vim moieties in hydrogels was the same for all of five samples. The amount of unloaded dye was determined by ultraviolet-visible (UV-vis) spectroscopy. The equilibrium adsorption capacity $\left(Q_{e}\right)$ was determined according to Equation (2):

$$
Q_{\mathrm{e}}=\frac{\left(C_{\mathrm{i}}-C_{\mathrm{e}}\right) V}{m}
$$

where $C_{\mathrm{i}}$ is the initial concentration of dyes in the mixture, $C_{\mathrm{e}}$ is the equilibrium concentration of dyes in the liquid phase, $V$ is the volume of the mixture and $m$ is the mass of the dried hydrogels. The kinetics of C4-1.8 hydrogels for adsorption of dyes were studied by mixing $0.02 \mathrm{~g}$ freeze-dried C4-1.8 hydrogels and $50 \mathrm{ml}$ dye solutions, that is, MO, MB, CR, OG, TB or $\mathrm{BTB}$, respectively. At each time interval, $2 \mathrm{ml}$ of the surrounding medium were sampled and determined by UV-vis spectroscopy.

Release of absorbed dyes from C4-1.8 hydrogels was investigated by immersing the dye-adsorbed hydrogels in $0.01 \mathrm{M} \mathrm{NaCl}$ aqueous solutions. Typically, weighed amounts of dye-adsorbed hydrogels were immersed into $50 \mathrm{ml} \mathrm{NaCl}$ aqueous solutions $(0.01 \mathrm{M})$. At each time interval, $2 \mathrm{ml}$ of the surrounding medium were sampled and replaced with $2 \mathrm{ml}$ of fresh $\mathrm{NaCl}$ aqueous solutions $(0.01 \mathrm{M})$. The sampled solutions were measured by UV-vis spectroscopy.

Adsorption isotherm of dyes on C4-1.8 hydrogels was also investigated. MO, $\mathrm{MB}$ and $\mathrm{CR}$ solutions with the concentrations of $7.6 \times 10^{-5}, 1.5 \times 10^{-4}$, $2.3 \times 10^{-4}, \quad 3.1 \times 10^{-4}, \quad 3.8 \times 10^{-4}, \quad 4.6 \times 10^{-4}, \quad 5.3 \times 10^{-4}, \quad 6.1 \times 10^{-4}$, $7.6 \times 10^{-4}$ and $9.2 \times 10^{-4} \mathrm{~mol}^{-1}$ were prepared for the batch-mode adsorption. The adsorption behavior of hydrogels was measured as follows: freezedried C4-1.8 hydrogels $(0.02 \mathrm{~g})$ were put into $25 \mathrm{ml}$ dye solutions with a predetermined concentration until the adsorption equilibrium was achieved. Concentrations of dyes in solutions before and after adsorption were determined by UV-vis spectroscopy. The equilibrium adsorption capacity $\left(Q_{\mathrm{e}}\right)$ was calculated by Equation (2).

\section{Instrumentation}

${ }^{1} \mathrm{H}$ NMR spectra were recorded on a $400 \mathrm{MHz}$ Varian Mercury Plus NMR instrument (Palo Alto, CA, USA) with $\mathrm{D}_{2} \mathrm{O}$ as solvent. The morphologies of obtained PNIPAm-based ionic hydrogels were obtained by using a scanning electron microscopy (Hitachi S4800 electron microscope, Tokyo, Japan). The samples for scanning electron microscopy measurements were freeze-dried and coated with platinum vapors before measurements. Fourier transform infrared spectra were recorded on a Vector 22 Bruker spectrometer (Karlsruhe, Germany). UV-vis spectra were recorded on a Cary 100 instrument (Varian, Melbourne, VIC, Australia).

\section{RESULTS AND DISCUSSION}

Synthesis and characterization of PNIPAm-based ionic hydrogels PNIPAm-based ionic hydrogels were obtained by free-radical copolymerization of NIPAm and IL crosslinker, $\left[\mathrm{C}_{n}(\mathrm{Vim})_{2}\right] \mathrm{Br}_{2}(n=3,4,6)$, in an aqueous solution with the presence of potassium peroxodisulfate initiator and TEMED accelerator, as described in the Experimental procedure section. Five hydrogels were obtained by changing the type and amounts of crosslinkers, respectively. Figure 1 shows the scanning electron microscopy images of the cross-section of five hydrogels, which were swollen in aqueous solutions and then freeze dried. The freeze-dried hydrogels showed porous structures. Obvious pores were observed for C4-3.6 and C4-9.0 hydrogels. While for C3-1.8, C4-1.8 and C6-1.8 hydrogels, pores were not obvious and there were many folds on the surface. It was probably due to the reason that $\mathrm{C} 3-1.8$, C4-1.8 and C6-1.8 hydrogels with lower crosslinking degrees had larger pores after swollen, and such larger pores might be easier to collapse after freeze dried.

Fourier transform infrared spectroscopy measurements were carried out to confirm the composition of hydrogels. Figure 2 shows the Fourier transform infrared spectroscopy spectra of the five ionic hydrogels. The characteristic bands at 1642,1543 and $1458 \mathrm{~cm}^{-1}$ could be ascribed to the $\mathrm{C}=\mathrm{O}$ stretching vibration, $\mathrm{N}-\mathrm{H}$ stretching vibration and the methyl group asymmetric bending vibrations of the PNIPAm segments, respectively. The characteristic bands at 3070 and $834 \mathrm{~cm}^{-1}$ could be assigned to the $\mathrm{C}-\mathrm{H}$ stretching vibrations and out-of-plane deformation vibrations of imidazole rings of Vim segments, respectively. These results showed that the PNIPAm-based hydrogels crosslinked with $\left[\mathrm{C}_{n}(\mathrm{Vim})_{2}\right] \mathrm{Br}_{2}$ were successfully obtained.

Figure 3 shows the swelling kinetics of the obtained PNIPAm-based ionic hydrogels. It is clearly discernable that all the hydrogels reached swelling equilibrium after $600 \mathrm{~min}$. The equilibrium SRs of the ionic hydrogels were listed in Table 1 , which were strongly dependent on the alkyl chain length $n$ and the amounts of $\left[\mathrm{C}_{n}(\mathrm{Vim})_{2}\right] \mathrm{Br}_{2}$ crosslinkers. The equilibrium SRs of C3-1.8, C4-1.8 and C6-1.8 hydrogels decreased with increasing the alkyl chain length $n$ of crosslinker when the amounts of $\left[\mathrm{C}_{n}(\mathrm{Vim})_{2}\right] \mathrm{Br}_{2}$ crosslinkers were fixed to be $1.8 \%$. It is reasonable because the longer alkyl chain length of crosslinker was the more hydrophobic the resultant hydrogel, leading to the lower equilibrium SR. In addition, when fixing the alkyl chain length but increasing the amounts of crosslinker, the equilibrium SR decreased from 45 to 33 and 20 for C4-1.8, C4-3.6 and C4-9.0 hydrogels. More crosslinkers increased the crosslinking density of the hydrogel networks, causing the decrease of equilibrium SR.

\section{Interfacial adsorption and release of anionic dyes in aqueous solutions}

Since the obtained PNIPAm-based ionic hydrogels crosslinked with $\left[\mathrm{C}_{n}(\mathrm{Vim})_{2}\right] \mathrm{Br}_{2}$ possessed quaternized Vim moieties, such ionic hydrogels exhibited strongly interfacial interactions with anionic dyes. These ionic hydrogels were capable to interfacial adsorb and release anionic dyes in aqueous solutions. Six anionic dyes, that is, MO, MB, CR, OG, TB and BTB were then studied. Scheme 2 shows the chemical structures of six anionic dyes.

The adsorption capacities of PNIPAm-based ionic hydrogels for $\mathrm{MO}, \mathrm{MB}$ and CR were first studied, as shown in Figure 4a. Note that the molar ratios of anionic dyes in aqueous solutions to quaternized Vim moieties in hydrogels were kept the same for all the samples. The $Q_{\mathrm{e}}$ values were determined by immersing freeze-dried hydrogels into dye solutions for 30 days to ensure adsorption equilibrium. The amounts of unloaded dyes were determined by UV-vis spectroscopy. The standard curves for UV adsorption of dyes were listed in Supplementary Figure S2. As seen from Figure $4 \mathrm{a}$, the adsorption capacities of C3-1.8, C4-1.8 and C6-1.8 hydrogels for the same dye were the same, which indicated that the alkyl chain length $n$ of crosslinkers did not affect the adsorption capacities of resultant hydrogels. For C4-1.8, C4-3.6 and C4-9.0 hydrogels, the adsorption capacities for $\mathrm{MO}$ and $\mathrm{MB}$ increased with increasing the amounts of $\left[\mathrm{C}_{4}(\mathrm{Vim})_{2}\right] \mathrm{Br}_{2}$ crosslinkers while the adsorption capacities for $\mathrm{CR}$ were the same. For MO and MB, the quaternized Vim moieties and the corresponding alterable counter anions in hydrogels via interfacial 

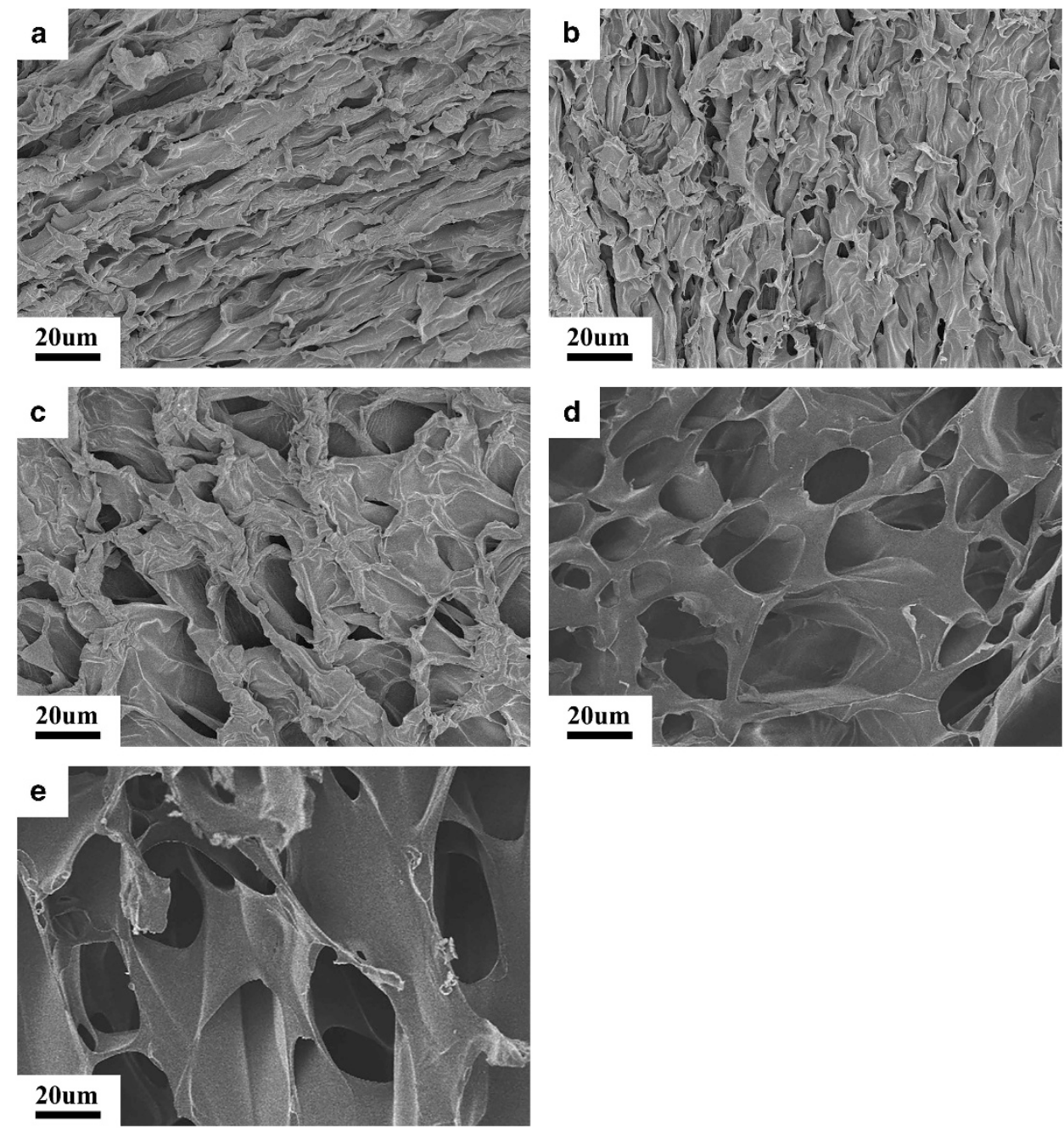

Figure 1 Scanning electron microscopy (SEM) images of poly( $N$-isopropylacrylamide)-based (PNIPAm)-based ionic hydrogels with sample code of (a) C3-1.8, (b) C4-1.8, (c) C6-1.8, (d) C4-3.6 and (e) C4-9.0, respectively.

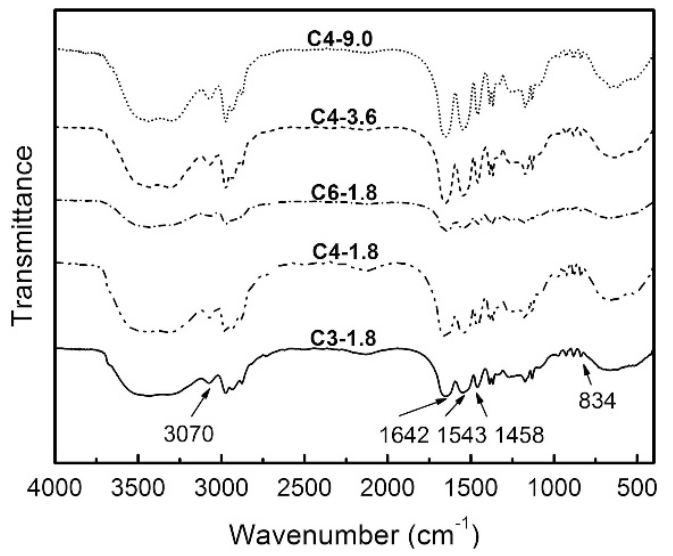

Figure 2 The Fourier transform infrared spectroscopy (FTIR) spectra of the obtained poly( $N$-isopropylacrylamide)-based (PNIPAm)-based ionic hydrogels.

ionic interaction increased with increasing the amounts of crosslinkers, leading to more adsorbed anionic dyes. However, CR has larger size, less planar geometry and greater value of free energy of

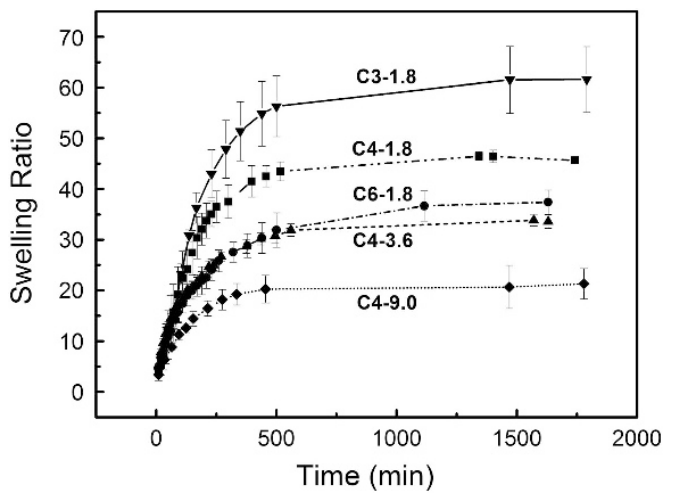

Figure 3 Swelling kinetics of the obtained poly( $N$-isopropylacrylamide)-based (PNIPAm)-based ionic hydrogels.

solvation than $\mathrm{MO}$ and $\mathrm{MB} .{ }^{39}$ The molecular size and surface area of $\mathrm{CR}$ are $2.65 \times 1.10 \times 0.25 \mathrm{~nm}$ and $2.92 \mathrm{~nm}^{2}$, respectively. ${ }^{40}$ The CPK models of MO, MB and CR were listed in Supplementary Figure S3. The adsorption capacities of all hydrogels for CR were almost similar. The inset of Figure 4a shows the photo of CR-adsorbed hydrogel with 


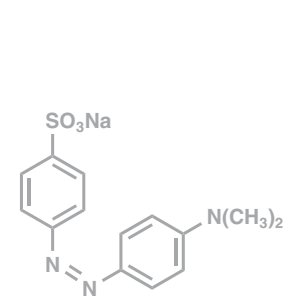

MO

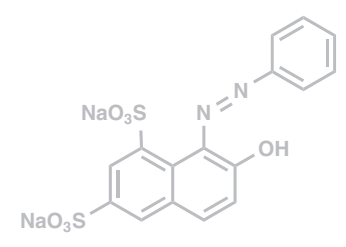

$O G$<smiles>COS(=O)(=O)c1ccc(N=C2C=CC(=C(c3ccc(Nc4ccc(S(C)(=O)=O)cc4)cc3)c3ccc(Nc4ccc(S(=O)(=O)O)cc4)cc3)C=C2)cc1</smiles>

MB<smiles>CC1=CC(=O)C(C(C)C)=CC1=C(c1cc(C)c(O)cc1C)c1ccccc1O</smiles>

TB

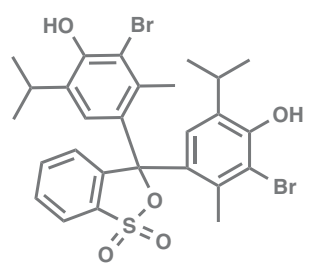

BTB

Scheme 2 Chemical structures of methyl orange (MO), methyl blue (MB), congo red (CR), orange G (OG), thymol blue (TB) and bromothymol blue (BTB). A full color version of this scheme is available at Polymer Journal online.
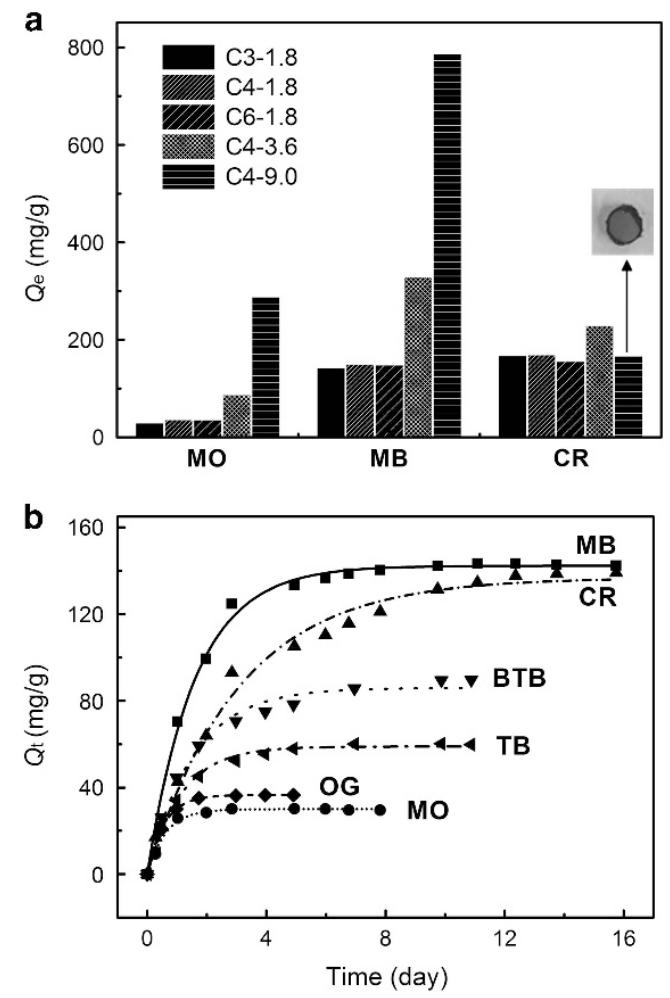

Figure 4 (a) The equilibrium adsorption capacities of $\operatorname{poly}(\mathrm{N}$ isopropylacrylamide)-based (PNIPAm)-based ionic hydrogels for methyl orange (MO), methyl blue (MB), congo red (CR), respectively. The inset shows the photo of CR-adsorbed hydrogel with sample code of C4-9.0. (b) The adsorption kinetics of C4-1.8 hydrogels for MO, MB, CR, OG, thymol blue (TB) and bromothymol blue (BTB). The lines were fits with the pseudofirst-order kinetics, that is, Equation (3).

sample code of C4-9.0. The color of edge of the hydrogel was much deeper than that of center, which indicated that the CR tended to be adsorbed onto the surface of the ionic hydrogels.

The adsorption kinetics of the obtained PNIPAm-based ionic hydrogels for adsorption of anionic dyes were further studied.
Figure $4 \mathrm{~b}$ shows the adsorption of six dyes on C4-1.8 hydrogels as a function of time. The observed adsorption behavior could be well described by the pseudo-first-order kinetics, given as:

$$
\log \left(Q_{\mathrm{e}}-Q_{\mathrm{t}}\right)=\log Q_{e}-\frac{k_{1} t}{2.303}
$$

where $Q_{\mathrm{e}}$ and $Q_{\mathrm{t}}$ are the amounts of dye adsorbed at equilibrium and at time $t$, respectively; $k_{1}$ is the rate constant of pseudo-first-order adsorption. The rate constant $k_{1}$, equilibrium adsorption amount $Q_{\mathrm{e}}$ and correlation coefficients $\left(R^{2}\right)$ were summarized in Supplementary Table S1. Moreover, the sequence of adsorption capacity after adsorption for 16 days was $\mathrm{MB}_{799.80}>\mathrm{CR}_{696.68}>\mathrm{BTB}_{624.38}>\mathrm{TB}_{466.59}>\mathrm{OG}_{452.37}>\mathrm{MO}_{327.32}$, which might indicate that the obtained PNIPAm-based ionic hydrogels preferred to adsorb anionic dyes with larger molecular weight. Note that the subscript represented the molecular weight of the anionic dye.

Figure 5 shows the adsorption isotherms of $\mathrm{MO}, \mathrm{MB}$ and $\mathrm{CR}$ absorbed onto C4-1.8 hydrogels in aqueous solutions at room temperature. The adsorption isotherms were described with Langmuir and Freundlich models, respectively. Langmuir ${ }^{41}$ proposed a theory to describe the adsorption of gas molecules onto metal surfaces. It has also been applied to many other sorption processes and used to explain the monolayer adsorption of dyes over a homogeneous surface $^{42}$ Freundlich ${ }^{43}$ demonstrated that the ratio of the amount of solute adsorbed onto a given mass of adsorbent to the concentration of the solute in the solution was not a constant at different solution concentrations. It was derived by assuming a heterogeneous surface with a non-uniform distribution of heat of adsorption over the surface. The linearized Langmuir and Freundlich isotherms are given as Equations (4) and (5), respectively.

$$
\begin{aligned}
& \frac{C_{\mathrm{e}}}{Q_{e}}=\frac{C_{\mathrm{e}}}{Q_{\mathrm{m}}}+\frac{1}{K_{\mathrm{L}} Q_{\mathrm{m}}} \\
& \ln Q_{\mathrm{e}}=\ln K_{\mathrm{F}}+\frac{1}{n} \ln C_{\mathrm{e}}
\end{aligned}
$$

where $K_{\mathrm{L}}$ is the Langmuir adsorption constant $\left(\mathrm{mg}^{-1}\right)$ related to energy of adsorption, $Q_{\mathrm{m}}$ signifies adsorption capacity $\left(\mathrm{mg} \mathrm{g}^{-1}\right), K_{\mathrm{F}}$ is Freundlich constant $\left(\mathrm{lmg}^{-1}\right)$ and $1 / n$ is the heterogeneity factor. The 

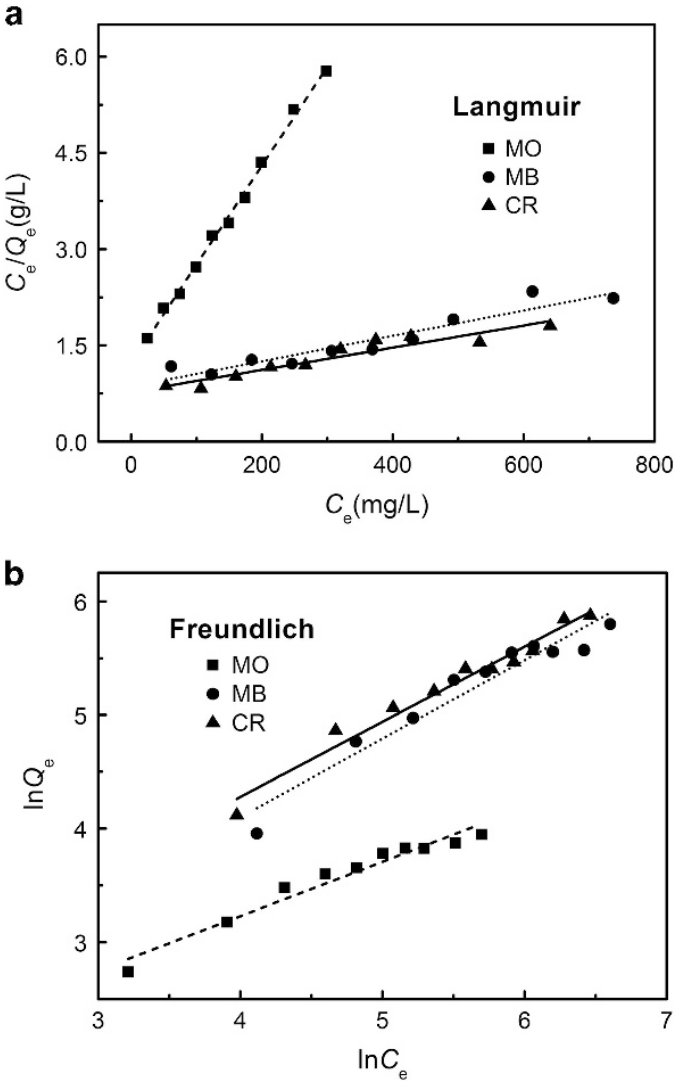

Figure 5 Adsorption isotherms of C4-1.8 hydrogels for methyl orange (MO), methyl blue (MB) and congo red (CR) at room temperature. The lines were fitted with Langmuir (a) and Freundlich (b) adsorption models, respectively.

Table 2 Isotherm parameters for adsorption of MO, MB and CR by C4-1.8 hydrogels at room temperature

\begin{tabular}{lccccccc}
\hline & \multicolumn{3}{c}{ Langmuir model } & & \multicolumn{3}{c}{ Freundlich model } \\
\cline { 2 - 3 } \cline { 6 - 7 } Dye & $\mathrm{K}_{L}$ & $\mathrm{Q}_{m}$ & $\mathrm{R}^{2}$ & & $K_{F}$ & $1 / \mathrm{n}$ & $\mathrm{R}^{2}$ \\
\hline MO & 0.0127 & 64.8 & 0.995 & & 3.730 & 0.478 & 0.951 \\
MB & 0.0023 & 505.1 & 0.887 & & 3.795 & 0.691 & 0.927 \\
CR & 0.0022 & 578.0 & 0.888 & & 5.124 & 0.661 & 0.966 \\
\hline
\end{tabular}

Abbreviations: $\mathrm{CR}$, congo red; $K_{\mathrm{L}}$, Langmuir constant; $K_{\mathrm{F}}$, Freundlich constant; MB, methyl blue; MO, methyl orange; $Q_{m}$, adsorption capacity; $1 / n$, heterogeneity factor.

fitting parameters of the Langmuir and Freundlich isotherm models as well as the correlation coefficients $\left(R^{2}\right)$ were given in Table 2. The adsorption behavior of MO onto C4-1.8 hydrogels were more close to the prediction of Langmuir isotherm, which could be applied to monolayer adsorption. While for $\mathrm{MB}$ and $\mathrm{CR}$, Freundlich isotherm was more suitable. These results indicated that the same adsorbent behaved differently for the adsorption of different anionic dyes, which was consistent with Paritosh's results. ${ }^{44}$ Similar results have been reported for adsorption of $\mathrm{MO}$ on surfactant modified silkworm exuviae $^{45}$ or carboxymethyl cellulose-g-poly(2-(dimethylamino) ethyl methacrylate) hydrogel, ${ }^{46} \mathrm{MB}$ adsorption on barium phosphate nanoflake ${ }^{47}$ or magnetic carbon nanotube, ${ }^{48}$ and CR adsorption on cyclophosphazene-bridged mesoporous organosilicas. ${ }^{44}$ Values of $1 / n$
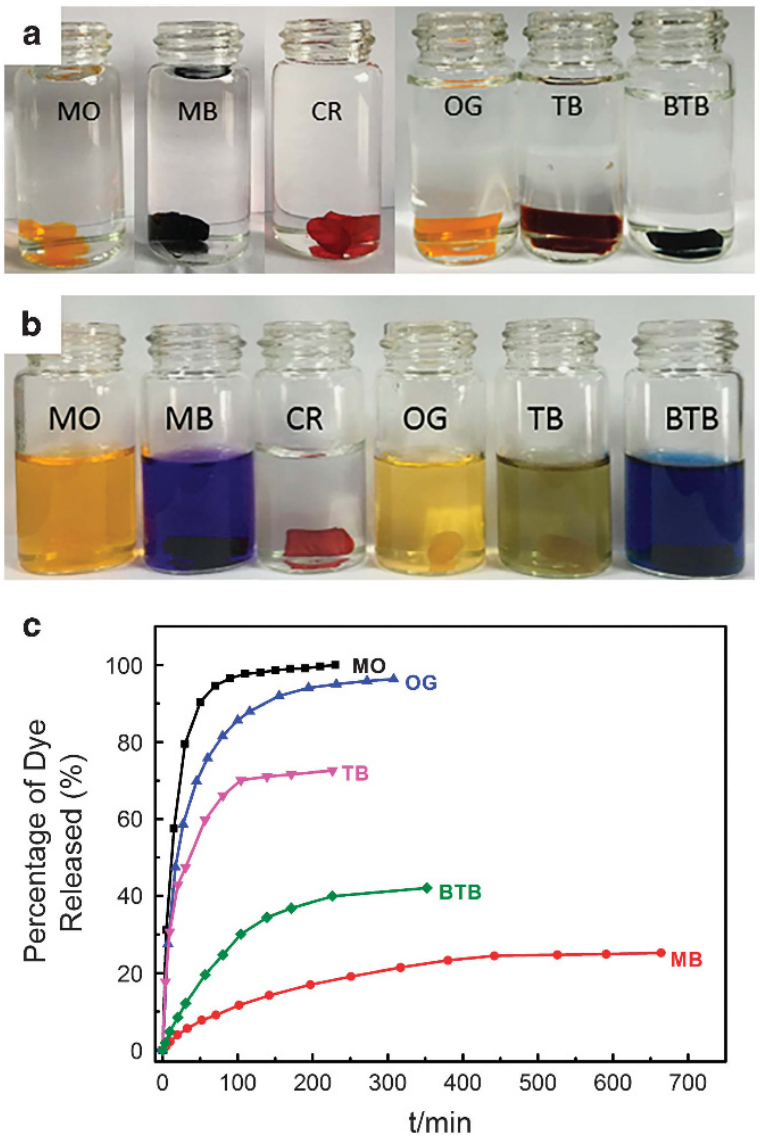

Figure 6 Dyes-adsorbed PNIPAm-based ionic hydrogels immersed in water (a) and $0.01 \mathrm{~m} \mathrm{NaCl}$ aqueous solutions (b). (c) Release profiles of dyes from the dyes-adsorbed PNIPAm-based ionic hydrogels as a function of time in $0.01 \mathrm{~m} \mathrm{NaCl}$ aqueous solutions.

$<1$ show the favorable nature of adsorption of $\mathrm{MO}, \mathrm{MB}$ and $\mathrm{CR}$ on C4-1.8 hydrogels. ${ }^{49}$ The maximum adsorption capacities of C4-1.8 hydrogels for MO, MB and CR were $64.8,505.1$ and $578.0 \mathrm{mg} \mathrm{g}^{-1}$, respectively. These values were higher compared with the results reported for adsorption of $\mathrm{MO}$ on poly(AM-co-DADMAC)/silica sol $\left(31.31 \mathrm{mg} \mathrm{g}^{-1}\right),{ }^{50} \mathrm{MB}$ adsorption on magnetic carbon nanotube $\left(115.34 \mathrm{mg} \mathrm{g}^{-1}\right)^{48}$ and CR adsorption on chitosan hydrogel beads impregnated with carbon nanotubes $\left(450.4 \mathrm{mg} \mathrm{g}^{-1}\right)^{51}$ or magnetic chitosan/poly(vinyl alcohol) hydrogel beads $\left(470.1 \mathrm{mg} \mathrm{g}^{-1}\right),{ }^{52}$ respectively.

The adsorbed anionic dyes could be released from the PNIPAmbased ionic hydrogels via the anion exchange reaction, as shown in Figure 6. By immersing the dye-adsorbed hydrogels in $0.01 \mathrm{M}$ $\mathrm{NaCl}$ aqueous solution, $\mathrm{MO}, \mathrm{MB}, \mathrm{OG}, \mathrm{TB}$ and $\mathrm{BTB}$ could be gradually released from the ionic hydrogels (cf. Figure 6c). For about $700 \mathrm{~min}$, all of the dye-adsorbed hydrogels reached release equilibrium. By anion exchange, $\mathrm{MO}$ and $\mathrm{OG}$ were almost completely released and ca. 70\% TB, 40\% BTB and 25\% MB were released, respectively. The sequence of equilibrium release was $\mathrm{MO}_{327.32}>\mathrm{OG}_{452.37}>\mathrm{TB}_{466.59}>\mathrm{BTB}_{624.38}>\mathrm{MB}_{799.80}>\mathrm{CR}_{696.68}$, which was substantially the opposite to the sequence of equilibrium adsorption capacity as shown in Figure 4b. The anionic dyes with more complex chemical structure and larger molecular weight exhibited stronger interfacial interaction with PNIPAm-based ionic hydrogels and the adsorbed anionic dyes were then more stable within the hydrogel networks. Interestingly, the CR dye formed very stable 
ionic association with PNIPAm-based ionic hydrogels and did not release any more, which might be probably due to the rod-like bulky structure with two anionic sulfonate groups located at both ends of the molecule (cf. Scheme 2). The ionic interactions between quaternized Vim moieties and anionic sulfonate groups might strongly entrap the $\mathrm{CR}$ molecules into the hydrogel networks like pseudo-crosslinking. These results suggested that the PNIPAm-based ionic hydrogels obtained in the present work might have potential and promising applications for dye loading and controlled release and the treatment of wastewater with anionic dye contamination.

\section{CONCLUSION}

Poly( $N$-isopropylacrylamide)-based ionic hydrogels were successfully synthesized by free-radical polymerization with NIPAm as the monomer and imidazolium-based dicationic IL as the crosslinker. The obtained ionic hydrogels had porous structures, good swelling properties and exhibited strongly interfacial interaction with anionic dyes in aqueous solution, which were strongly dependent on the chemical structures of the anionic dyes. The interfacial adsorption kinetic of anionic dyes on the obtained ionic hydrogels could be described by the pseudo-first-order kinetics. The anionic dyes with more complex chemical structure and larger molecular weight exhibited stronger interfacial interactions with PNIPAm-based ionic hydrogels.

\section{CONFLICT OF INTEREST}

The authors declare no conflict of interest.

\section{ACKNOWLEDGEMENTS}

We thank the National Natural Science Foundation of China (Nos. 21274129 and 21322406), the Fundamental Research Funds for the Central Universities (2014XZZX003-21) and the third level of 2013 Zhejiang Province 151 Talent Project for financial supports.

1 Chen, Q., Zhu, L., Zhao, C., Wang, Q. \& Zheng, J. A robust, one-pot synthesis of highly mechanical and recoverable double network hydrogels using thermoreversible sol-gel polysaccharide. Adv. Mater. 25, 4171-4176 (2013)

2 Tan, M., Zhao, T., Huang, H. \& Guo, M. Highly stretchable and resilient hydrogels from the copolymerization of acrylamide and a polymerizable macromolecular surfactant. Polym. Chem. 4, 5570-5576 (2013).

3 Sun, J., Zhao, X., Illeperuma, W. R. K., Chaudhuri, O., Oh, K. H., Mooney, D. J., Vlassak, J. J. \& Suo, Z. Highly stretchable and tough hydrogels. Nature 489 133-136 (2012).

4 Li, Z., Xiang, Y., Zhou, X., Nie, J., Peng, M. \& Du, B. Thermo-sensitive poly(DEGMMA-co-MEA) microgels: synthesis, characterization and interfacial interaction with adsorbed protein layer. Chin. J. Polym. Sci. 33, 1516-1526 (2015).

5 Vermonden, T., Censi, R. \& Hennink, W. E. Hydrogels for protein delivery. Chem. Rev. $112,2853-2888$ (2012).

$6 \mathrm{Kim}$, D. \& Beebe, D. J. Hydrogel-based reconfigurable components for microfluidic devices. Lab Chip 7, 193-198 (2007)

7 Buenger, D., Topuz, F. \& Groll, J. Hydrogels in sensing applications. Prog. Polym. Sci. 37, 1678-1719 (2012).

8 Lee, K. Y. \& Mooney, D. J. Hydrogels for tissue engineering. Chem. Rev. 101, 1869-1879 (2001).

9 Kopecek, J. Hydrogels: from soft contact lenses and implants to self-assembled nanomaterials. J. Polym. Sci. Part A 47, 5929-5946 (2009)

10 Calvert, P. Hydrogels for soft machines. Adv. Mater. 21, 743-756 (2009).

11 Peppas, N. A., Hilt, J. Z., Khademhosseini, A. \& Langer, R. Hydrogels in biology and medicine: from molecular principles to bionanotechnology. Adv. Mater. 18, 1345-1360 (2006).

12 Slaughter, B. V., Khurshid, S. S., Fisher, O. Z., Khademhosseini, A. \& Peppas, N. A. Hydrogels in regenerative medicine. Adv. Mater. 21, 3307-3329 (2009).

13 Van Vlierberghe, S., Dubruel, P. \& Schacht, E. Biopolymer-based hydrogels as scaffolds for tissue engineering applications: a review. Biomacromolecules 12 1387-1408 (2011).

14 Sangeetha, N. M. \& Maitra, U. Supramolecular gels: functions and uses. Chem. Soc. Rev. 34, 821-836 (2005).
15 Nguyen, K. T. \& West, J. L. Photopolymerizable hydrogels for tissue engineering applications. Biomaterials 23, 4307-4314 (2002).

16 Yu, L. \& Ding, J. Injectable hydrogels as unique biomedical materials. Chem. Soc. Rev. 37, 1473-1481 (2008).

17 Parvulescu, V. I. \& Hardacre, C. Catalysis in ionic liquids. Chem. Rev. 107, 2615-2665 (2007).

18 Yuan, J., Soll, S., Drechsler, M., Mueller, A. H. E. \& Antonietti, M. Self-assembly of poly (ionic liquid)s: polymerization, mesostructure formation, and directional alignment in one step. J. Am. Chem. Soc. 133, 17556-17559 (2011).

19 Armand, M., Endres, F., MacFarlane, D. R., Ohno, H. \& Scrosati, B. Ionic-liquid materials for the electrochemical challenges of the future. Nat. Mater. 8 , 621-629 (2009).

20 Giernoth, R. Task-specific ionic liquids. Angew. Chem. Int. Ed. 49, 2834-2839 (2010).

21 Xiong, Y., Liu, J., Wang, Y., Wang, H. \& Wang, R. One-step synthesis of thermosensitive nanogels based on highly cross-linked poly(ionic liquid)s. Angew. Chem. Int. Ed. 51, 9114-9118 (2012)

22 Suzuki, K., Yamaguchi, M., Hotta, S., Tanabe, N. \& Yanagida, S. A new alkyl-imidazole polymer prepared as an inonic polymer electrolyte by in situ polymerization of dye sensitized solar cells. J. Photochem. Photobiol. A 164, 81-85 (2004).

23 Li, F., Cheng, F., Shi, J., Cai, F., Liang, M. \& Chen, J. Novel quasi-solid electrolyte for dye-sensitized solar cells. J. Power Sources 165, 911-915 (2007).

24 Zhang, Y., Zhao, L., Patra, P. K., Hu, D. \& Ying, J. Y. Colloidal poly-imidazolium salts and derivatives. Nano Today 4, 13-20 (2009).

25 Yuan, C., Guo, J. \& Yan, F. Shape memory poly(ionic liquid) gels controlled by hostguest interaction with beta-cyclodextrin. Polymer 55, 3431-3435 (2014).

26 Yuan, C., Guo, J., Si, Z. \& Yan, F. Polymerization in ionic liquid-based microemulsions. Polym. Chem. 6, 4059-4066 (2015).

27 Yuan, C., Guo, J., Tan, M., Guo, M., Qiu, L. \& Yan, F. Multistimuli responsive and electroactive supramolecular gels based on ionic liquid gemini guest. ACS Macro Lett. 3, 271-275 (2014)

28 Crini, G. Non-conventional low-cost adsorbents for dye removal: a review. Bioresour Technol. 97, 1061-1085 (2006).

29 Forgacs, E., Cserhati, T. \& Oros, G. Removal of synthetic dyes from wastewaters: a review. Environ. Int. 30, 953-971 (2004).

30 Bhattacharyya, K. G. \& Sharma, A. Kinetics and thermodynamics of methylene blue adsorption on neem (azadirachta indica) leaf powder. Dyes Pigm 65, 51-59 (2005).

31 Alves de Lima, RO, Bazo, AP, Salvadori, DM, Rech, CM, de Palma Oliveira, D \& de Aragão Umbuzeiro, G. Mutagenic and carcinogenic potential of a textile azo dye processing plant effluent that impacts a drinking water source. Mutat. Res. Genet. Toxicol. Environ. Mutagen 626, 53-60 (2007).

32 Carneiro, P. A., Umbuzeiro, G. A., Oliveira, D. P. \& Zanoni, M. V. B. Assessment of water contamination caused by a mutagenic textile effluent/dyehouse effluent bearing disperse dyes. J. Hazard. Mater. 174, 694-699 (2010).

33 Nguyen, Le, M. T. \& Lee, B. K. High temperature synthesis of interfacial functionalized carboxylate mesoporous $\mathrm{TiO} 2$ for effective adsorption of cationic dyes. Chem. Eng. J. 281, 20-33 (2015)

34 Hao, O. J., Kim, H. \& Chiang, P. C. Decolorization of wastewater. Crit. Rev. Environ. Sci. Technol. 30, 449-505 (2000).

35 Zhou, X., Zhou, Y., Nie, J., Ji, Z., Xu, J., Zhang, X. \& Du, B. Thermosensitive ionic microgels via surfactant-free emulsion copolymerization and in situ quaternization cross-linking. ACS Appl. Mater. Interfaces 6, 4498-4513 (2014).

36 Zhou, X., Nie, J., Wang, Q. \& Du, B. Thermosensitive ionic microgels with pH tunable degradation via in situ quaternization cross-linking. Macromolecules $\mathbf{4 8}$ 3130-3139 (2015).

37 Zhou, X., Nie, J., Xu, J. \& Du, B. Thermo-sensitive ionic microgels via post quaternization cross-linking: fabrication, property, and potential application. Colloid. Polym. Sci. 293, 2101-2111 (2015).

38 Zhou, X., Nie, J. \& Du, B. 4-(2-Pyridylazo)-resorcinol functionalized thermosensitive ionic microgels for optical detection of heavy metal ions at nanomolar level. ACS Appl. Mater. Interfaces 7, 21966-21974 (2015).

39 Sandeman, S. R., Gun'ko, V. M., Bakalinska, O. M., Howell, C. A., Zheng, Y., Kartel, M. T., Phillips, G. J. \& Mikhalovsky, S. V. Adsorption of anionic and cationic dyes by activated carbons, PVA hydrogels, and PVA/AC composite. J. Colloid Interface Sci. 358, 582-592 (2011).

40 Chen, T., Du, B. \& Fan, Z. Organic-inorganic hybrid mesoporous polymers fabricated by using $(\mathrm{CTA})(2)_{2} \mathrm{O}_{8}$ as self-decomposed soft templates. Langmuir $\mathbf{2 8}$ 15024-15032 (2012).

41 Langmuir, I. The adsorption of gases on plane surfaces of glass, mica and platinum. J. Am. Chem. Soc. 40, 1361-1403 (1918).

42 Mall, I. D., Srivastava, V. C. \& Agarwal, N. K. Removal of orange-G and methyl violet dyes by adsorption onto bagasse fly ash-kinetic study and equilibrium isotherm analyses. Dyes Pigm 69, 210-223 (2006).

43 Freundlich, H. Concerning adsorption in solutions. J. Phys. Chem. 57, 385 (1906).

44 Rekha, P., Muhammad, R. \& Mohanty, P. Sonochemical synthesis of cyclophosphazene bridged mesoporous organosilicas and their application in methyl orange, congo red and Cr(VI) removal. RSC Adv. 5, 67690-67699 (2015).

45 Chen, H., Zhao, J., Wu, J. \& Dai, G. Isotherm, thermodynamic, kinetics and adsorption mechanism studies of methyl orange by surfactant modified silkworm exuviae. J. Hazard. Mater. 192, 246-254 (2011).

46 Salama, A., Shukry, N. \& El-Sakhawy, M. Carboxymethyl cellulose-g-poly(2-(dimethylamino) ethyl methacrylate) hydrogel as adsorbent for dye removal. Int. J. Biol. Macromol. 73, 72-75 (2015). 
47 Zhang, F., Zhao, Z., Tan, R., Guo, Y., Cao, L., Chen, L., Li, J., Xu, W., Yang, Y. \& Song, W. Selective and effective adsorption of methyl blue by barium phosphate nanoflake. J. Colloid Interface Sci. 386, 277-284 (2012).

48 Wang, S., Gao, Q., Luo, W. J., Xu, J., Zhou, C. G. \& Xia, H. Removal of methyl blue from aqueous solution by magnetic carbon nanotube. Water Sci. Technol. 68, 665-673 (2013)

49 Dawood, S., Sen, T. K. \& Phan, C. Synthesis and characterisation of novel-activated carbon from waste biomass pine cone and its application in the removal of congo red dye from aqueous solution by adsorption. Water Air Soil Pollut. 225 (2014).
50 Yang, X. \& Ni, L. Synthesis of hybrid hydrogel of poly(AM co DADMAC)/silica sol and removal of methyl orange from aqueous solutions. Chem. Eng. J. 209, 194-200 (2012).

51 Chatterjee, S., Lee, M. W. \& Woo, S. H. Adsorption of congo red by chitosan hydrogel beads impregnated with carbon nanotubes. Bioresour. Technol. 101, 1800-1806 (2010)

52 Zhu, H. Y., Fu, Y. Q., Jiang, R., Yao, J., Xiao, L. \& Zeng, G. M. Novel magnetic chitosan/ poly(vinyl alcohol) hydrogel beads: preparation, characterization and application for adsorption of dye from aqueous solution. Bioresour. Technol. 105, 24-30 (2012).

Supplementary Information accompanies the paper on Polymer Journal website (http://www.nature.com/pj) 